\title{
Endurance of methanogenic archaea in anaerobic bioreactors treating oleate-based wastewater
}

\author{
Andreia F. Salvador • Ana J. Cavaleiro • \\ Diana Z. Sousa • M. Madalena Alves • M. Alcina Pereira
}

Received: 4 January 2012 / Revised: 26 March 2012 / Accepted: 27 March 2012 /Published online: 9 May 2012

(C) Springer-Verlag 2012

\begin{abstract}
Methanogenic archaea are reported as very sensitive to lipids and long chain fatty acids (LCFA). Therefore, in conventional anaerobic processes, methane recovery during LCFA-rich wastewater treatment is usually low. By applying a start-up strategy, based on a sequence of step feeding and reaction cycles, an oleate-rich wastewater was efficiently treated at an organic loading rate of $21 \mathrm{~kg}$ COD $\mathrm{m}^{-3}$ day $^{-1}$ (50\% as oleate), showing a methane recovery of $72 \%$. In the present work, the archaeal community developed in that reactor is investigated using a 16S rRNA gene approach. This is the first time that methanogens present in a bioreactor converting efficiently high loads of LCFA to methane are monitored. Denaturing gradient gel electrophoresis profiling showed that major changes on the archaeal community took place during the bioreactor start-up, where phases of continuous feeding were alternated with batch phases. After the start-up, a stable archaeal community (similarity higher than $84 \%$ ) was observed and maintained throughout the continuous operation. This community exhibited high LCFA tolerance and high acetoclastic and hydrogenotrophic activity. Cloning and sequencing results showed that Methanobacterium- and Methanosaeta-like microorganisms prevailed in the system and were able to tolerate and endure during prolonged exposure to high LCFA loads, despite the previously reported LCFA sensitivity of methanogens.
\end{abstract}

\footnotetext{
A. F. Salvador $\cdot$ A. J. Cavaleiro $\cdot$ D. Z. Sousa $\cdot$ M. M. Alves $(\bowtie)$ M. A. Pereira Institute for Biotechnology and Bioengineering, Centre of Biological Engineering, University of Minho, Campus de Gualtar, 4710-057 Braga, Portugal e-mail: madalena.alves@deb.uminho.pt

M. A. Pereira

e-mail: alcina@deb.uminho.pt
}

Keywords Anaerobic treatment · High-rate bioreactor . LCFA $\cdot$ Methanogens $\cdot 16 \mathrm{~S}$ rRNA gene $\cdot$ PCR-DGGE

\section{Introduction}

Long chain fatty acid (LCFA) conversion to methane involves the activity and syntrophic collaboration of acetogenic bacteria, oxidizing LCFA to hydrogen and acetate, and methanogenic archaea, responsible for consuming hydrogen and acetate with the production of methane and carbon dioxide (Schink 1997). Hydrogen interspecies transfer is obligatory as it renders LCFA oxidation exergonic (Sousa et al. 2009). To guarantee a maximum methane production, acetate conversion to methane is crucial as well. Therefore, acetoclastic and hydrogenotrophic methanogenic activity should be maximized to achieve high methane yields in anaerobic digesters. However, it has been suggested that LCFA can exert inhibitory effect towards anaerobic microorganisms, in particular methanogens (Hwu and Lettinga 1997; Koster and Cramer 1987; Lalman and Bagley 2001; Perle et al. 1995). Adsorption of LCFA onto the microbial cell wall (Koster and Cramer 1987) and binding of LCFA to cell membranes with interference in transport functions (Hook et al. 2010; Soliva et al. 2004) have been suggested as potential mechanisms underlying inhibition by LCFA. Nevertheless, some authors documented only a transient inhibition and suggest that adaptation of microbial communities to LCFA may occur after extended exposure (Alves et al. 2001; Broughton et al. 1998; Kim et al. 2004; Pereira et al. 2004). Transport limitations, due to the accumulation of LCFA onto the sludge, could also contribute to the generally observed lag phases ascribed to microbial inhibition (Pereira et al. 2005). A sequential process, in which a first step of LCFA accumulation was promoted, followed by batch degradation of the biomass- 
associated substrate, was found to be a possible solution for the treatment of this type of wastewaters (Cavaleiro et al. 2008; Pereira et al. 2004). More recently, Cavaleiro et al. (2009) showed that continuous treatment of high LCFA loads can also be achieved after a start-up in cycles, alternating continuous feeding with batch phases. Based on these findings, a novel high rate anaerobic reactor specifically designed for the treatment of lipids/LCFA wastewaters has been developed (Alves et al. 2007, 2009). Sousa et al. (2007) used FISH and real-time polymerase chain reaction (PCR) for quantifying methanogens during fed-batch degradation of LCFA. Results showed that the relative abundance of archaea increased during degradation of biomass-accumulated LCFA. Two major groups of methanogens were identified: hydrogenand formate-utilizing organisms, closely related to Methanobacterium, and acetoclastic organisms closely related to Methanosaeta and Methanosarcina. Methanogenic communities in high rate continuous reactors efficiently degrading LCFA were never studied. In this work, we focused on the composition and dynamics of the archaeal community that colonized the anaerobic bioreactor described in the work of Cavaleiro et al. (2009), which was fed with a synthetic wastewater mainly composed of oleic acid (mono-unsaturated C18 LCFA).

\section{Materials and methods}

Sludge source A total of 15 sludge samples were collected during the operation of a mesophilic $\left(37^{\circ} \mathrm{C}\right)$ up-flow anaerobic column reactor fed with an oleate-rich wastewater as described by Cavaleiro et al. (2009). Table 1 shows sludge sampling times and a summary of the operating conditions and the performance data of the reactor.

The reactor was inoculated with anaerobic suspended sludge collected from a municipal sludge digester and its concentration was maintained stable around $20 \mathrm{~g} \mathrm{VS} \mathrm{L}^{-1}$. Reactor feed consisted of a mixture of skim milk and sodium oleate (50:50 \% COD) supplemented with macro- and micronutrients and bicarbonate, as previously described by Alves et al. (2001).

Five cycles of continuous feeding phases (F), alternated with batch reaction phases $(\mathrm{R})$, were applied during the first 213 days of operation (period I). During feeding phases, LCFA accumulation inside the bioreactor was favored, whereas degradation of the accumulated LCFA was promoted during reaction phases. Length of feeding and reaction phases was established based on the methane production efficiency and LCFA accumulation/degradation in the bioreactor mixed liquor (Cavaleiro et al. 2009). Period I corresponded to the system start-up and was followed by a continuous feeding period (period II, days 243-665). Reactor operation was interrupted from days 213 to 243 . Detailed description on bioreactor operation conditions can be found in the paper by Cavaleiro et al. (2009).

DNA extraction and amplification Aliquots of wellhomogenized sludge were immediately frozen at the time of sampling and stored at $-20^{\circ} \mathrm{C}$. Total genomic DNA was extracted using a FastDNA SPIN Kit for Soil (Qbiogene, Carlsbad, CA, USA) according to the manufacturer's instructions. 16S rRNA genes were amplified by PCR using a Taq DNA Polymerase kit (Life Technologies, Gaithersburg, MD, USA). Primer sets A109(T)-f/515-r and Uni1492-r/Arch109-f (Grosskopf et al. 1998; Lane 1991; Nübel et al. 1996) were used for 16S rRNA gene amplification for denaturing gradient gel electrophoresis (DGGE) and sequencing purposes, respectively; primer 515-r for DGGE analysis was modified by the addition of a 40-bp GC clamp at the $5^{\prime}$ end of the sequence. A description of PCR programs and primers sequences can be found in the paper by Sousa et al. (2007). All primers used were synthesized commercially by Invitrogen (Life Technologies). Size and yield of PCR products were estimated using a 100-bp DNA ladder (MBI Fermentas, Vilnius, Lithuania) via $1 \%$ $(\mathrm{wt} / \mathrm{vol})$ agarose gel electrophoresis and ethidium bromide staining.

$D G G E$ analysis DGGE analysis of the amplicons was performed as previously described by Zoetendal et al. (2001) by using the Dcode system (Bio-Rad, Hercules, CA, USA) with $8 \%(\mathrm{vol} / \mathrm{vol})$ polyacrylamide gels and a denaturant gradient of 30 to $60 \%$. A $100 \%$ denaturing solution was defined as $7 \mathrm{M}$ urea and $40 \%$ formamide. Electrophoresis was performed for $16 \mathrm{~h}$ at $85 \mathrm{~V}$ in $0.5 \times \mathrm{TAE}$ buffer at $60^{\circ} \mathrm{C}$. DGGE gels were stained with $\mathrm{AgNO}_{3}$ according to the procedure previously described by Sanguinetti et al. (1994). DGGE profiles were scanned at $400 \mathrm{dpi}$ and compared using the BioNumerics ${ }^{\mathrm{TM}}$ software package (version 5.0; Applied Maths BVBA, Sint-Martens-Latem, Belgium). Similarity between DGGE profiles was determined by calculating similarity indices of the densitometric curves of the compared profiles, using the Pearson product-moment correlation (Hane et al. 1993). Peak heights in the densitometric curves were used to determine the diversity indices based on the Shannon Wiener diversity index, calculated as follows:

$H=-\Sigma\left(P_{\mathrm{i}} \ln \left(P_{\mathrm{i}}\right)\right)$

where $H$ is the diversity index and $P_{\mathrm{i}}$ is the importance probability of the bands in a lane $\left(P_{\mathrm{i}}=n_{\mathrm{i}} / n\right.$, where $n_{\mathrm{i}}$ is the height of an individual peak and $n$ is the sum of all peak heights in the densitometric curves).

Cloning and sequencing of PCR-amplified products PCR products obtained from DNA samples corresponding to the 
Table 1 Sludge sampling times and summary of corresponding operating conditions and performance data (Cavaleiro et al. 2009)

\begin{tabular}{|c|c|c|c|c|c|}
\hline Period/operation mode & Phase $^{\mathrm{a}}$ & Time (days) & Sampling day & OLR $\left(\mathrm{kg} \mathrm{COD} \mathrm{m}^{-3}\right.$ day $\left.^{-1}\right)$ & Methane yield ${ }^{\mathrm{b}}(\%)$ \\
\hline \multirow[t]{10}{*}{ Period I (cycles) } & F-1 & $0-17$ & 0 & $4.4 \pm 0.6$ & \multirow[t]{2}{*}{ n.d. } \\
\hline & $\mathrm{R}-1$ & $17-45$ & 17 & n.a. & \\
\hline & $\mathrm{F}-2$ & $45-62$ & 45 & $4.4 \pm 0.6$ & \multirow[t]{2}{*}{66.7} \\
\hline & $\mathrm{R}-2$ & $62-100$ & 62 & n.a. & \\
\hline & F-3 & $100-117$ & 100 & $4.4 \pm 0.6$ & \multirow[t]{2}{*}{72.7} \\
\hline & R-3 & $117-138$ & - & n.a. & \\
\hline & $\mathrm{F}-4$ & $138-166$ & 138 & $4.4 \pm 0.6$ & \multirow[t]{2}{*}{ n.d. } \\
\hline & $\mathrm{R}-4$ & $166-181$ & - & n.a. & \\
\hline & F-5 & $181-203$ & 181 & $8.2 \pm 0.6$ & \multirow[t]{2}{*}{90.7} \\
\hline & $\mathrm{R}-5$ & $203-213$ & 213 & n.a. & \\
\hline Stop phase (sludge at $4^{\circ} \mathrm{C}$ ) & & $213-243$ & & & \\
\hline \multirow[t]{7}{*}{ Period II (continuous) } & $\mathrm{C}-1$ & $243-277$ & - & $5.0 \pm 0.4$ & 81.5 \\
\hline & $\mathrm{C}-2$ & $277-333$ & - & $7.8 \pm 1.0$ & 79.5 \\
\hline & $\mathrm{C}-3$ & $333-389$ & & $9.8 \pm 2.2$ & 86.0 \\
\hline & C-4 & $389-437$ & 389 & $11.5 \pm 2.2$ & 98.4 \\
\hline & C-5 & $437-571$ & $437 ; 494 ; 544$ & $20.6 \pm 4.0$ & 71.5 \\
\hline & C-6 & $571-608$ & $584 ; 599$ & $26.1 \pm 4.2$ & 60.9 \\
\hline & $\mathrm{C}-7$ & $608-665$ & 665 & $31.2 \pm 7.9$ & 57.0 \\
\hline
\end{tabular}

n.a. not applicable, $n . d$. not determined

${ }^{\text {a }} F$ feeding, $R$ reaction, $C$ continuous

${ }^{\mathrm{b}}$ Methane yield $(\%)=\mathrm{g}_{\mathrm{COD}-\mathrm{CH} 4 \text { produced }} / \mathrm{g}_{\mathrm{COD} \text { removed }} \times 100$

final time of periods I and II (days 213 and 665, respectively) were purified with Nucleo Spin Extract II kit (Clontech Laboratories) and cloned into E. coli ${ }^{\circledR} 10 \mathrm{G}$ Electrocompetent Cells (Lucigen ${ }^{\circledR}$ Corporation) by using Promega pGEM-T Easy vector system (Promega, Madison, WI, USA). PCR was performed on cell lysates of ampicillin-resistant transformants by using pGEM-T-specific primers PG1-f and PG2-r to confirm the size of the inserts. Clones with the correct size insert were further amplified with primer set A109(T)-f/515r for DGGE comparison with original sample profiles. PCR products of transformants resolving at the same position of predominant bands in the DGGE community fingerprint were chosen for further analysis. Selected clones were amplified with using pGEM-T vector-targeted primers SP6/T7, purified using the Nucleo Spin Extract II kit (Clontech Laboratories), and subjected to DNA sequence analysis. Sequencing reactions were performed at Biopremier (Lisbon, Portugal). Consensus sequences obtained were checked for potential chimera artifacts using Mallard v1.02 (Ashelford et al. 2006) and Pintail v1.1 (Ashelford et al. 2005) software.

Phylogenetic analysis Similarity searches for the 16S rRNA gene sequences derived from the sludge clones were performed using the NCBI BLAST search program within the GenBank database (http://www.ncbi.nlm.nih.gov/blast/) (Altschul et al. 1990). Alignment of 16S rRNA sequences was performed by using FastAligner V1.03 tool of the ARB program package (Ludwig et al. 2004). The resulting alignments were manually checked and corrected when necessary, and unambiguously aligned nucleotide positions were used for construction of the archaea 16S rRNA gene-based phylogenetic tree, using the neighbor-joining method (Saitou and Nei 1987). Phylogenetic placement was performed in comparison with reference sequences with Felsenstein correction and application of archaeal filter. Nucleotide sequences obtained in this study have been deposited in the European Nucleotide Archive (ENA) under accession numbers HE648042 to HE648052.

\section{Results}

Analysis of methanogenic communities during bioreactor start-up

Microbial diversity and shifts in archaeal communities present in the anaerobic bioreactor during the intermittent 
Fig. 1 DGGE pattern (a) and cluster analysis (b) of archaeal 16S rRNA gene fragments obtained from samples collected during the reactor start-up (period I). Cluster analysis was performed using the unweighted pairwise grouping method with mathematical averages (UPGMA). Numbers 0 to 213 correspond to sampling days during period I and DGGE bands analyzed by cloning and sequencing are identified

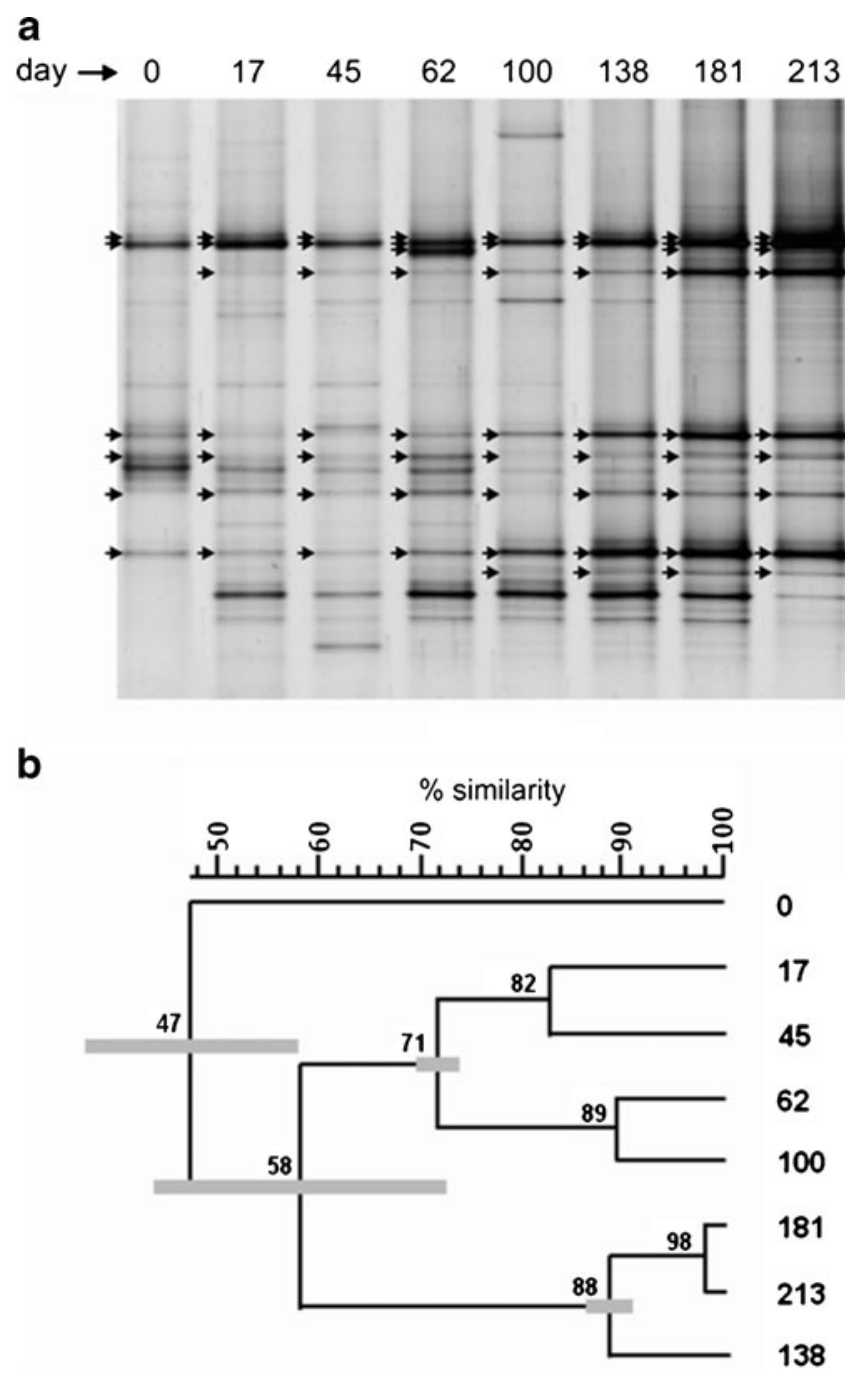

feeding start-up were estimated by $16 \mathrm{~S}$ rRNA gene PCRDGGE (Fig. 1). Analysis of eight sludge samples withdrawn from the reactor during start-up period (Table 1) revealed a shift in the archaeal communities overtime, with samples grouping in three main clusters (Fig. 1b). The inoculum sludge ( $t=0$ days) showed the lowest diversity (Shannon diversity index of 0.67 ) and shared only $47 \%$ similarity with the other sludge samples; there was a fast shift in the archaeal community after contacting with oleate and skim milk (reactor sludge sample withdrawn on day 17 is only $67 \%$ similar to the inoculum sludge). Similarity between samples collected during the first and second cycle of sludge acclimation (until day 100 of bioreactor operation) and samples from subsequent cycles (from days 138 to 213 ) is $58 \%$. On the other hand, samples collected on days 138 , 181 , and 213 are $88 \%$ similar, and almost no variation on the archaeal communities structure was observed between samples collected during the fifth cycle (corresponding to samples from days 181 and 213) as they share $98 \%$ similarity (Fig. 1b). This means that major shifts in the archaeal community took place during the first two cycles of the start-up operation.

Endurance of methanogenic communities in continuous high rate bioreactor

Period II of operation corresponds to continuous reactor feeding with an increasing organic loading rate (OLR) of up to $31.2 \mathrm{~kg} \mathrm{COD} \mathrm{m} \mathrm{m}^{-3} \mathrm{day}^{-1}$ (50\% COD as sodium oleate) (Table 1). Figure 2 shows the DGGE profiles of archaeal $16 \mathrm{~S}$ rRNA fragments obtained from seven different sludge samples collected during that period (from days 389 to 665) as well as the corresponding similarity index dendrogram. Similarity between the obtained profiles was always higher than $84 \%$ and fluctuated between 89 and $98 \%$ within the five last samples. Shannon diversity indices $(H)$ decreased $28 \%$ from the sample collected on days 389 to 437 , and from this moment on, the variation of the diversity indices was very low (less than $12 \%$ of variation) showing the stability of the archaeal community diversity during the continuous bioreactor operation. 
Fig. 2 DGGE pattern (a) and cluster analysis (b) of archaeal 16S rRNA gene fragments obtained from samples collected during the reactor continuous operation (period II). Cluster analysis was performed using the unweighted pairwise grouping method with mathematical averages (UPGMA). Numbers 389 to 665 correspond to sampling days during period II and DGGE bands analyzed by cloning and sequencing are identified

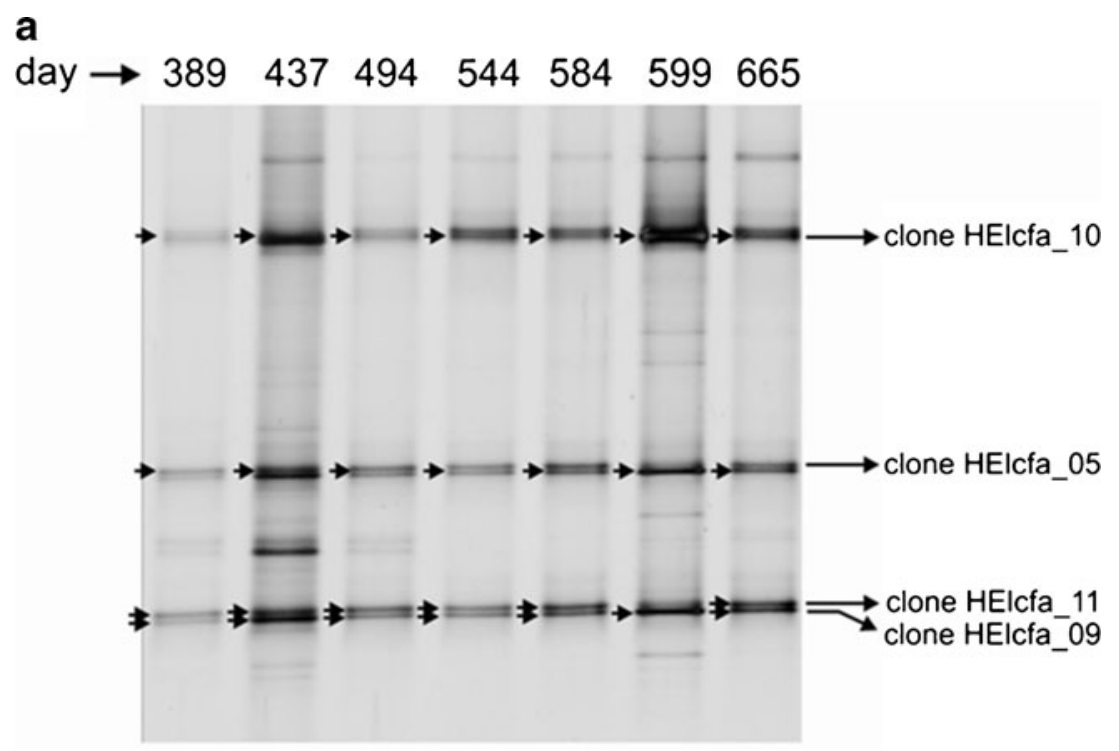

b

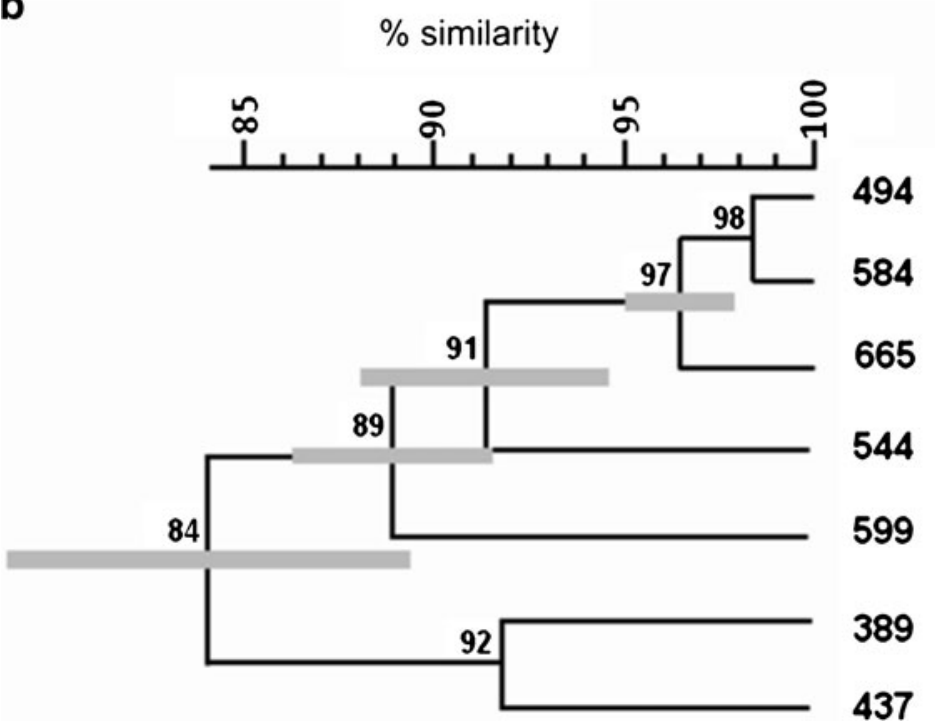

Phylogenetic analysis of predominant bands in the archaeal DGGE patterns

To assign the composition of the predominant community visualized in the DGGE patterns, nearly full-length archaeal $16 \mathrm{~S}$ rRNA gene fragments, retrieved from the sludge sample collected at the end of the start-up period (day 213) and at the end of the continuous period (day 665), were used to construct clone libraries. Clones with the same electrophoretic mobility as that of predominant bands of archaeal DGGE patterns were selected for further sequence analysis. Phylogenetic affiliation of sequences was initially assessed by BLAST similarity searches and RDP Classifier and confirmed by secondary structure-assisted alignment and phylogenetic analysis (Fig. 3). Clones 5 and 9 were originated from the sample collected on day 213 (end of period I). Their correspondence to bands present in the sample collected on day 665 was made by comparing the electrophoretic mobility of the PCR products.

The retrieved $16 \mathrm{~S}$ rRNA sequences were affiliated with methanogenic archaea belonging to the phylum Euryarchaeota and to the orders Methanobacteriales and Methanosarcinales (Fig. 3). At the end of the start-up period, retrieved sequences showed higher similarity to those of Methanobacterium sp. OM15 (99\%) (clones HElcfa_03 and HElcfa_04), Methanobacterium beijingense 8-2 (98\%)(clones HElcfa_01 and HElcfa_02), and Methanosaeta concilii GP-6 (99 \%) (clones HElcfa_05 to HElcfa_09), according to BLAST searches. The analysis of $16 \mathrm{~S}$ rRNA sequences obtained at the end of period II revealed the presence of the same genera, namely Methanosaeta and Methanobacterium (Fig. 3). Retrieved sequences were most related with the sequences of the following methanogens: $M$. concilii GP-6 (99\% of similarity) (clones HElcfa_05, HElcfa_09, and 
Fig. 3 Phylogenetic tree of archaeal 16S rRNA gene sequences retrieved from the sludge samples collected at the end of both operational periods, period I and period II. Trees were calculated using the ARB software package (Ludwig et al. 2004) and applying the neighbor-joining method (Saitou and Nei 1987). Closely related sequences, with the respective ENA accession number, are shown as reference. Archaeoglobus fulgidus (AE000965) was used as outgroup for archaea tree. Reference bars indicate $10 \%$ sequence divergence

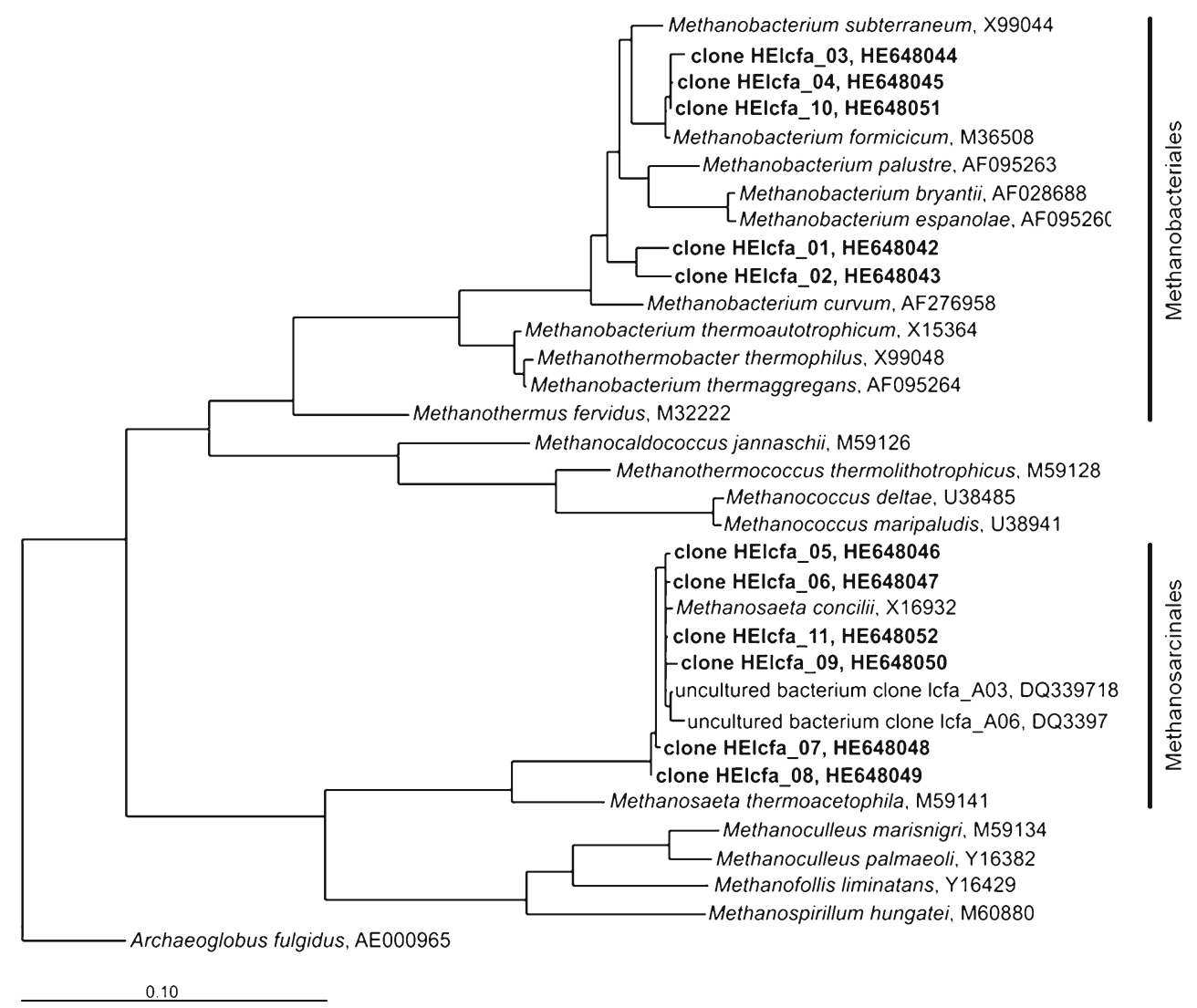

HElcfa_11) and Methanobacterium sp. OM15 (99\% of similarity) (clone HElcfa_10).

\section{Discussion}

Key methanogenic groups showing high LCFA tolerance and high methanogenic activity were identified through molecular characterization of the archaeal community present in the anaerobic bioreactor. Methanobacterium- and Methanosaeta-like microorganisms prevailed in the system (Fig. 3) during alternating feeding and batch cycles (period I) and continuous operation (period II) and likely contributed to the high methane production observed. Maximum specific methane production rates around $1,000 \mathrm{mg} \mathrm{COD}-\mathrm{CH}_{4} \mathrm{~g}$ $\mathrm{VS}^{-1}$ day $^{-1}$ were achieved in the bioreactor when OLR of 26-31 kg COD m ${ }^{-3}$ day $^{-1}$ were applied, showing that LCFA were not inhibiting the methanogens (Cavaleiro et al. 2009). Moreover, the specific methanogenic activity of this consortia increased considerably, i.e., from nondetectable values to $497 \pm 19 \mathrm{~mL} \mathrm{CH}_{4} \mathrm{~g} \mathrm{VS}^{-1}$ day $^{-1}$ in acetate and from $56 \pm 6$ to $1,322 \pm 174 \mathrm{~mL} \mathrm{CH}_{4} \mathrm{~g} \mathrm{VS}^{-1}$ day $^{-1}$ in hydrogen (Cavaleiro et al. 2009).

Although the presence of Methanobacterium- and Methanosaeta-like microorganisms has been previously reported in anaerobic bioreactors fed with LCFA (Bertin et al. 2004; Grabowski et al. 2005; Ince et al. 2003; Pereira et al. 2005;
Rizzi et al. 2006; Sousa et al. 2007), this is the first study in which the two methanogenic genera are shown to tolerate and endure during extended contact with LCFA loads higher than $10 \mathrm{~kg} \mathrm{COD} \mathrm{m}^{-3}$ day $^{-1}$.

LCFA accumulation inside the bioreactor reached a maximum concentration of $44 \mathrm{mM}(23 \mathrm{mM}$ palmitate and $21 \mathrm{mM}$ stearate) at the end of the second cycle (period I). These concentration values are much higher than reported $\mathrm{IC}_{50}$ (concentration that causes a $50 \%$ relative methanogenic activity loss). At mesophilic temperatures, $\mathrm{IC}_{50}$ values for oleate towards acetoclastic methanogens range from 0.1 to $4.35 \mathrm{mM}$ (Alves et al. 2001; Hwu and Lettinga 1997; Koster and Cramer 1987; Pereira et al. 2005). This wide range of $\mathrm{IC}_{50}$ values is justified by the different parameters than can influence oleate toxicity, namely (1) the type of anaerobic sludge (Hwu and Lettinga 1997), (2) presence of divalent cations in the medium (Koster and Cramer 1987; Roy et al. 1985), and (3) potential biomass adaptation (Alves et al. 2001). $\mathrm{IC}_{50}$ values towards the acetoclastic methanogens were also reported for linoleate (C18:2), stearate (C18:0), and palmitate (C16:0), i.e., $0.8,5.4$, and $4.3-6 \mathrm{mM}$, respectively (Pereira et al. 2005; Shin et al. 2003).

Bioreactor feeding strategy changed drastically from period I (cycles) to period II (continuous) but methanogenic community composition did not, since the same archaeal groups were identified (Fig. 3). According to the DGGE profile (Fig. 1), the most relevant changes on the 
methanogenic community occurred during cycles 1 and 2 of period I. Archaeal community diversity remained stable until the end of the experiment, i.e., diversity indices varied less than $12 \%$ and similarity between profiles was higher than $84 \%$ (Fig. 2). Only during the first 100 days of the bioreactor operation, LCFA accumulation was observed and was efficiently biodegraded by the anaerobic consortium thereafter (Cavaleiro et al. 2009). This dynamics of LCFA accumulation/degradation probably contributed to the establishment of a methanogenic community adapted to the presence of high oleate concentrations. Besides acclimation of archaeal cells, high efficiency of the LCFA-degrading bacteria might also have contributed to the endurance of the prevailing methanogens.

The results obtained in this work emphasize that a correct equilibrium between LCFA adsorption and biodegradation can trigger microbial community adaptation, as previously suggested by Alves et al. (2001) and Pereira et al. (2004). The results also suggest that methanogenic microorganisms belonging to Methanobacterium and Methanosaeta genera are important to achieve efficient LCFA conversion to methane in continuous high rate anaerobic bioreactors treating LCFA rich wastewater.

Acknowledgments This study has been financially supported by FEDER funds through the Operational Competitiveness Programme (COMPETE) and by national funds through the Portuguese Foundation for Science and Technology (FCT) in the frame of the projects FCOMP-01-0124-FEDER-007087 and FCOMP-01-0124-FEDER014784. Financial support from FCT and the European Social Fund (ESF) through $\mathrm{PhD}$ grants SFRH/BD/48960/2008 and SFRH/BD/ 24256/2005 attributed to Andreia Salvador and Ana Júlia Cavaleiro is also acknowledged.

\section{References}

Altschul SF, Gish W, Miller W, Meyers EW, Lipman DJ (1990) Basic local alignment search tool. J Mol Biol 215:403-410. doi:10.1016/S0022-2836(05)80360-2

Alves MM, Vieira JA, Pereira RM, Pereira MA, Mota M (2001) Effects of lipids and oleic acid on biomass development in anaerobic fixed-bed reactors. Part II: oleic acid toxicity and biodegradability. Water Res 35:264-270. doi:10.1016/S0043-1354(00) 00242-6

Alves MM, Picavet MA, Pereira MA, Cavaleiro AJ, Sousa DZ (2007) Novel anaerobic reactor for the removal of long chain fatty acids from fat containing wastewater. WO2007058557

Alves MM, Pereira MA, Sousa DZ, Cavaleiro AJ, Picavet M, Smidt H, Stams AJM (2009) Waste lipids to energy: how to optimize methane production from long-chain fatty acids (LCFA). Microb Biotechnol 2:538-550. doi:10.1111/j.1751-7915.2009.00100.x

Ashelford KE, Chuzhanova NA, Fry JC, Jones AJ, Weightman AJ (2005) At least 1 in 20 16S rRNA sequence records currently held in public repositories is estimated to contain substantial anomalies. Appl Environ Microbiol 71:7724-7736. doi:10.1128/ AEM.71.12.7724-7736.2005

Ashelford KE, Chuzhanova NA, Fry JC, Jones AJ, Weightman AJ (2006) New screening software shows that most recent large 16S
rRNA gene clone libraries contain chimeras. Appl Environ Microbiol 72:5734-5741. doi:10.1128/AEM.00556-06

Bertin L, Colao MC, Ruzzi M, Fava F (2004) Performances and microbial features of a granular activated carbon packed-bed biofilm reactor capable of an efficient anaerobic digestion of olive mill wastewaters. FEMS Microbiol Ecol 48:413-423. doi:10.1016/j.femsec.2004.03.009

Broughton MJ, Thiele JH, Birch EJ, Cohen A (1998) Anaerobic batch digestion of sheep tallow. Water Res 32:1423-1428. doi:10.1016/ S0043-1354(97)00345-X

Cavaleiro AJ, Pereira MA, Alves MM (2008) Enhancement of methane production from long chain fatty acid based effluents. Bioresour Technol 99:4086-4095. doi:10.1016/j.biortech.2007.09.005

Cavaleiro AJ, Salvador AF, Alves JI, Alves M (2009) Continuous high rate anaerobic treatment of oleic acid based wastewater is possible after a step feeding start-up. Environ Sci Technol 43:2931-2936. doi:10.1021/es8031264

Grabowski A, Blanchet D, Jeanthon C (2005) Characterization of longchain-fatty-acid-degrading syntrophic associations from a biodegraded oil reservoir. Res Microbiol 156:814-821. doi:10.1016/ j.resmic.2005.03.009

Grosskopf R, Janseen PH, Liesack W (1998) Diversity and structure of the methanogenic community in anoxic rice paddy soil microcosms as examined by cultivation and direct $16 \mathrm{~S}$ rRNA gene sequence retrieval. Appl Environ Microbiol 64:960-969

Hane BG, Jager K, Drexler HG (1993) The Pearson product-moment correlation coefficient is better suited for identification of DNA fingerprint profiles than band matching algorithms. Electrophoresis 14:967-972. doi:10.1002/elps.11501401154

Hook SE, Wright A-DG, McBride BW (2010) Methanogens: methane producers of the rumen and mitigation strategies. Archaea 2010: 11 pages. doi:10.1155/2010/945785

Hwu C-S, Lettinga G (1997) Acute toxicity of oleate to acetateutilizing methanogens in mesophilic and thermophilic anaerobic sludges. Enzyme Microb Technol 21:297-301. doi:10.1016/ S0141-0229(97)00050-1

Ince BK, Ince O, Oz NA (2003) Changes in acetoclastic methanogenic activity and microbial composition in an upflow anaerobic filter. Water Air Soil Pollut 144:304-315

Kim S-H, Han S-K, Shin H-S (2004) Two-phase anaerobic treatment system for fat-containing wastewater. J Chem Technol Biotechnol 79:63-71. doi:10.1002/jctb.939

Koster IW, Cramer A (1987) Inhibition of methanogenesis from acetate in granular sludge by long-chain fatty acids. Appl Environ Microbiol 53:403-409

Lalman JA, Bagley DM (2001) Anaerobic degradation and methanogenic inhibitory effects of oleic and stearic acids. Water Res 35:2975-2983. doi:10.1016/S0043-1354(00)00593-5

Lane DJ (1991) 16S/23S rRNA sequencing. In: Stackebrandt E, Goodfellow M (eds) Nucleic acid techniques in bacterial systematics. Wiley, Chichester, pp 115-175

Ludwig W, Strunk O, Westram R, Richter L, Meier H, Yadhukumar AB, Buchner A, Lai T, Steppi S, Jobb G, Förster W, Brettske I, Gerber S, Ginhart AW, Gross O, Grumann S, Hermann S, Jost R, König A, Liss T, Lußmann R, May M, Björn N, Reichel B, Strehlow R, Stamatakis A, Stuckmann N, Vilbig A, Lenke M, Ludwig T, Bode A, Schleifer K-H (2004) ARB: a software environment for sequence data. Nucleic Acids Res 32:1363-1371. doi: $10.1093 / \mathrm{nar} / \mathrm{gkh} 293$

Nübel U, Engelen B, Felske A, Snaidr J, Wieshuber A, Amann RI, Ludwig W, Backhaus H (1996) Sequence heterogeneities of genes encoding 16S rRNAs in Paenibacillus polymyxa detected by temperature gradient gel electrophoresis. J Bacteriol 178:56365643

Pereira MA, Sousa DZ, Mota M, Alves MM (2004) Mineralization of LCFA associated with anaerobic sludge: kinetics, enhancement of 
methanogenic activity, and effect of VFA. Biotechnol Bioeng 88:502-511. doi:10.1002/bit.20278

Pereira MA, Pires OC, Mota M, Alves MM (2005) Anaerobic biodegradation of oleic and palmitic acids: evidence of mass transfer limitations caused by long chain fatty acid accumulation onto the anaerobic sludge. Biotechnol Bioeng 92:15-23. doi:10.1002/ bit.20548

Perle M, Kimchie S, Shelef G (1995) Some biochemical aspects of the anaerobic degradation of dairy wastewater. Water Res 29:15491554. doi:10.1016/0043-1354(94)00248-6

Rizzi A, Zucchi M, Borin S, Marzorati M, Sorlini C, Daffonchio D (2006) Response of methanogen populations to organic load increase during anaerobic digestion of olive mill wastewater. J Chem Technol Biotechnol 81:1556-1562. doi:10.1002/jctb.1558

Roy F, Albagnac G, Samain E (1985) Influence of calcium addition on growth of highly purified syntrophic cultures degrading longchain fatty acids. Appl Environ Microbiol 49:702-705

Saitou N, Nei M (1987) The neighbor-joining method: a new method for reconstructing phylogenetic trees. Mol Biol Evol 4:406-425

Sanguinetti CJ, Dias Neto E, Simpson AJ (1994) Rapid silver staining and recovery of PCR products separated on polyacrylamide gels. Biotechniques 17:914-921
Schink B (1997) Energetics of syntrophic cooperation in methanogenic degradation. Microbiol Mol Biol Rev 61:262-280

Shin H-S, Kim S-H, Lee C-Y, Nam S-Y (2003) Inhibitory effects of long-chain fatty acids on VFA degradation and $\beta$-oxidation. Water Sci Technol 47:139-146

Soliva CR, Meile L, Cieslak A, Kreuzer M, Machmuller A (2004) Rumen simulation technique study on the interactions of dietary lauric and myristic acid supplementation in suppressing ruminal methanogenesis. Br J Nutr 92:689-700. doi:10.1079/ BJN20041250

Sousa DZ, Pereira MA, Smidt H, Stams AJ, Alves MM (2007) Molecular assessment of complex microbial communities degrading long chain fatty acids in methanogenic bioreactors. FEMS Microbiol Ecol 60:252-265. doi:10.1111/j.1574-6941.2007.00291.x

Sousa DZ, Smidt H, Alves MM, Stams AJ (2009) Ecophysiology of syntrophic communities that degrade saturated and unsaturated long-chain fatty acids. FEMS Microbiol Ecol 68:257-272. doi:10.1111/j.1574-6941.2009.00680.x

Zoetendal EG, Akkermans ADL, Akkermans van Vliet WM, de Visser JAGM, de Vos WM (2001) The host genotype affects the bacterial community in the human gastrointestinal tract. Microbiol Ecol Health Dis 13:129-134. doi:10.1080/089106001750462669 